\title{
COVID-19, Acute Lymphoblastic Leukemia, and Down Syndrome: A Short Review and a Case Report
}

\author{
Ahmed Arafat ${ }^{a, b}$ Dinara Sadykova ${ }^{a, b} \quad$ Ayrat Ziatdinova, $^{a}$ \\ Svetlana Senek ${ }^{a, b} \quad$ Natalya Samoilova ${ }^{a, b}$ Tamara Makarovaa, b \\ ${ }^{a}$ Kazan State Medical University, Kazan, Russian Federation; ${ }^{b}$ Children's Republican Clinical \\ Hospital, Kazan, Russian Federation
}

\section{Keywords}

Corona virus disease 2019 - Acute lymphoblastic leukemia · Down syndrome · Infectious disease

\begin{abstract}
SARS-CoV-2 which causes COVID-19 has been a great challenge to treat and deal with; despite strict measures that had been implemented by governments and organizations, worrying rates of morbidity and mortality are still being reported. Although available data have expressed that moderate or even mild forms of the disease are expected amongst most pediatrics cases, minimal data are available on the prognosis and the disease's complications on the immunocompromised, especially oncology patients. We report a case of relapsed precursor B-cell acute lymphoblastic leukemia of a child with Down syndrome and COVID-19 and outline the treatment regimen that we used.
\end{abstract}

\section{Introduction}

Early reports from China have shown that children are less susceptible toward being severely affected by COVID-19 [1]. At the same time however, children with underlying serious health conditions such as cardiovascular disease, chronic pulmonary disease, and immunosuppression (e.g., related to chemotherapy, radiation, and malignancy) appear to be at a higher risk of contracting a severe form of COVID-19 [2].

The most common malignancy in adolescents and children alike is acute lymphoblastic leukemia (ALL) [3, 4]. A consensus approach to classifying the risk and management of

\section{Karger!}


children with ALL defined children who are aged 1-9.99 years and with initial WBC count $<50,000$ per cubic millimeter as standard risk, while children aged $\geq 10$ years, with initial WBC count $\geq 50,000$ per cubic millimeter, or both are classified as high risk [5]. Infants, older teenagers, Down syndrome (DS) patients, and those who are on intensive therapy are at high risk of death.

Studies have expressed better outcomes of patients with acute myeloid leukemia (AML) and DS than ALL and DS patients [6]. That is most likely due to resistance of trisomic lymphoblasts to cytotoxic drugs, unlike the better response to cytotoxic drugs of myeloblasts from patients with DS and AML, which accounts for better curable rates [7]. Patients of DS have been showing higher frequencies of altered levels of drug toxicities or more commonly, mucositis, cardiotoxicity, infections, and myelosuppression [8]. DS patients are at higher risks of H1N1- and respiratory syncytial virus-related mortalities and higher rates of mortality due to pneumonia and sepsis [9].

According to the Respiratory Syncytial Virus (RSV) Gold study, children with DS are highly susceptible to death resulting from RSV [10]. A Mexican team during the H1N1 2009 pandemic showed worrying results of increased morbidity and mortality in DS patients, with 335 -fold greater deaths, 8-fold more intubation, and 16-fold more of the possibility of hospitalization [9]. High incidence of autoimmune disorders, elevated production of cytokines, and the characteristic chronic dysregulation of the immune system in DS patients make them more vulnerable to COVID-19 and RSV infections, with the related cause of mortality always pointing at cytokine release syndrome [11]. However, studies on DS patients and COVID-19 in children are rare, which makes it unclear how severe the outcome in those patients might be.

Confirmed COVID-19 in a child with ALL was first reported in early March 2020, in Wuhan, China [12], with rapid progression of his pulmonary lesion and with respiratory support as treatment. Children with hematological malignancies are probably more susceptible to infection with SARS-COV-2 due to immunodeficiency.

Here, we present a case of SARS-CoV-2 in a child with relapsed ALL and DS and report the clinical findings as well as the successful treatment procedures. To the best of our knowledge, this is the first case report of infection of COVID-19 in ALL children with DS.

\section{Case Presentation}

A 6-year and 6-month-old boy with combined relapse (central nervous system [CNS] and bone marrow) ALL and DS was admitted to our department after his mother's second smear tested positive for COVID-19 while he was receiving his relapse treatment within ALL-REZBFM-2002 protocol, and his test for COVID-19 was negative.

\section{Present History}

Upon admission, he was $20.7 \mathrm{~kg}$, with a heart rate of $120 \mathrm{bpm}$, a blood pressure of 115/66 $\mathrm{mm} \mathrm{Hg}$, no detection of clinical complaints nor apparent lymphadenopathy, no catarrhal inflammation of the mucous membranes, no hepatosplenomegaly, and auscultation of both heart and chest revealed no abnormalities. His body temperature was $36.9^{\circ} \mathrm{C}$. Laboratory studies were normal except for white blood cell count: $6.01 \mathrm{~K} / \mu \mathrm{L}$, with $62 \%$ neutrophils and $19.5 \%$ lymphocytes. Coagulation profile: fibrinogen $2.9 \mathrm{~g} / \mathrm{L}$, INR: $0.94 \%$, and thrombin time: $30 \mathrm{~s}$. His mother did not have any complaints, and her laboratory studies were unremarkable.

Co-trimoxazole $240 \mathrm{mg}$ orally, 3 times a day, 3 days a week (Fri, Sat, and Sun), was prescribed to the child, with close monitoring of the symptoms. Reduction of the chemotherapy by one-third if needed was advised to avoid toxicity, and chest CT was requested only when necessary to avoid excessive radiation exposure. Oxygen saturation $\left(\mathrm{SPO}_{2}\right)$ was $96-99 \%$.

\section{Karger'}



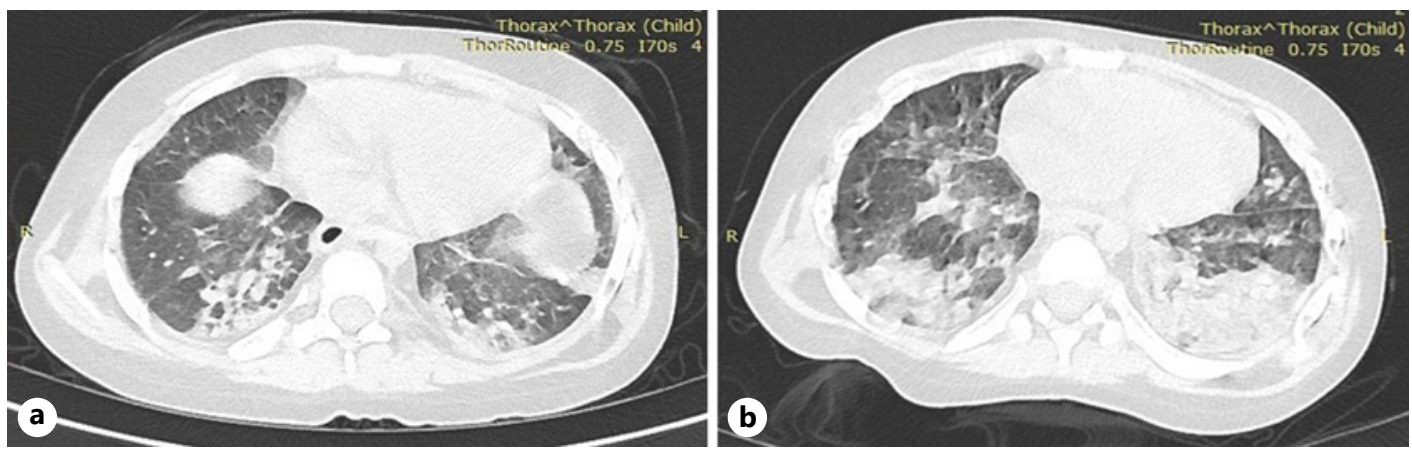

Fig. 1. Chest CT scans of our patient. a Chest CT performed on the 6th day of admission shows patchy nodular consolidations with peripheral ground-glass opacities in subpleural areas of the lower lobes of both lungs and bilateral pneumonia. $\mathbf{b}$ The second chest CT which was performed a few days after the first one shows the worsening of the condition with an increase in the size of the previously described areas (a) and the identification of new areas of increased lung tissue density and consolidation.

On the 6th day of admission, the patient started to develop a fluctuating fever up to $39^{\circ} \mathrm{C}$, and CT was ordered which revealed the following: 2 extensive areas of increased density with air bronchogram on both lungs, rough pleuropulmonary adhesions in the upper and lower lobes of both lungs, signs of diminished air entry on both lungs, patchy nodular consolidations with peripheral ground-glass opacities in subpleural areas of the lower lobes of both lungs, and bilateral pneumonia (Fig. 1a). Oropharyngeal swab continued to test negative for SARS$\mathrm{CoV}-2$. At this stage, his laboratory studies were normal except for white blood cell count: 4.96 $\mathrm{K} / \mu \mathrm{L}$, with $61 \%$ neutrophils and $18 \%$ lymphocytes. Despite CT findings, his $\mathrm{SPO}_{2}$ remained over $95 \%$.

Upon these findings and on the 8th day of admission, the following therapy was prescribed: hydroxychloroquine $(6.5 \mathrm{mg} / \mathrm{kg}$ orally twice per day on day 1 , followed by $3.25 \mathrm{mg} / \mathrm{kg}$ orally twice per day for 5 days), azithromycin (300 mg once a day for 5 days), and meropenem (20 $\mathrm{mg} / \mathrm{kg} /$ dose IV every $8 \mathrm{~h}$ ). During the first 2 days of therapy, the temperature rose to febrile numbers up to 3 times a day. CRP indicators were between 3.15 and $4.54 \mathrm{mg} / \mathrm{dL}$ and procalcitonin $0.368 \mathrm{ng} / \mathrm{mL}$, but no modification to the therapy was made.

On the 12th and the 14th days of admission, the oropharyngeal swabs were tested positive for SARS-CoV-2. A second chest CT was ordered on the 19th day of admission which showed an increase in the size of the previously described areas (Fig. 1a) and the identification of new areas of increased lung tissue density and consolidation (Fig. 1b).

Upon such findings, we made the following modifications: meropenem was stopped, co-trimoxazole was started to be given IV, tocilizumab (IL-6 inhibitor) was prescribed (8 mg/ $\mathrm{kg}$ IV slowly over $1 \mathrm{~h}$, diluted in $100 \mathrm{~mL} 0.45 \% \mathrm{NaCl}$ once), daily monitoring for coagulation profile, dalteparin was prescribed, $0.1 \mathrm{~mL}(2500 \mathrm{IU} / 0.2 \mathrm{~mL}) 2$ times a day, close monitoring for cytokine release syndrome through monitoring $\mathrm{SPO}_{2}$, blood pressure, CRP, IL-6, ferritin, D-dimer, and lactate dehydrogenase. Following the prescription of tocilizumab, dramatic improvements were noticed; laboratory results and the general condition of the patient started to improve, on the 4th and 6th days of prescribing tocilizumab (24th and 26th days of admission, respectively); oropharyngeal swabs tested negative for SARS-CoV-2.

After a follow-up for 6 days after prescribing tocilizumab, upon examination and before discharge, our patient's temperature was $36.6^{\circ} \mathrm{C}$, heart rate $90 \mathrm{bpm}$, the child was calm, the skin was clear and pink in color, no swelling nor congestion of mucous membranes, chest auscultation revealed equal air entry on both lungs with no wheezes, and normal rhythmic heart sounds. The abdomen was soft with no hepatosplenomegaly. Upon discharge from the 
hospital, laboratory results were all within a normal range (Table 1). The boy's mother tested negative for COVID-19 by PCR twice within a 48-h interval, and both the child and the mother were discharged after being cured successfully on the 26th day of admission.

\section{Treatment and Outcome Timeline}

The chronology of treatment, PCR results, CRP, and patient's clinical condition since the first day of admission until the day of discharge are shown in Table 2. A follow-up CT scan of the patient (see online suppl. Fig. 1) and laboratory tests' reference ranges according to our patient's gender and age (online suppl. Table 1) are shown in online suppl. File 1, available at www.karger.com/doi/10.1159/000516442.

\section{Discussion}

We report a case of combined CNS and bone marrow relapse of precursor B-cell ALL of a child with DS and COVID-19 and outline the treatment regimen that we used. Although first reports of patients with ALL and COVID-19 showed that only respiratory support was needed to achieve a successful cure [12], it was a huge challenge for our team to deal with this case, since it was presented with all of the possible risks of contracting a severe form of SARS-CoV-2, due to the following reasons: (1) it was initially diagnosed as high-risk ALL, (2) then the combined CNS and bone marrow relapse, which is known to have a bad prognosis and high mortality rates, (3) being a case of DS, with the known bad prognosis of patients with ALL and DS compared to patients with AML and DS, and the high incidence of infections and altered drug toxicity profile with DS patients, which have a high incidence of mortality due to pneumonia, sepsis, and RSV15, (4) COVID-19, which is known to cause severe acute respiratory syndrome, (5) the likelihood of developing cytokine release syndrome, which is mainly caused by chronic dysregulation of the immune system, the high incidence of autoimmune disorders, and elevated production of cytokines that are common with DS patients, and (6) lack of guidelines and scarcity of reports (as of the time of writing this report) on the prognosis and how to deal with patients with immunosuppression (e.g., cancer and chemotherapy), DS, and COVID-19.

In our pediatric hemato-oncology center, alongside other centers worldwide [13], COVID-19 testing policy remains the same as that for the general population. With the increasing number of diagnosed COVID-19 cases globally, we would prefer a preemptive testing before invasive procedures to such patients [14].

A recent American study suggested that pediatric cases with cancer may not be susceptible to being severely affected by SARS-CoV-2 compared to other children. They also suggested testing of caregivers of the patients, as $17.6 \%$ of the caregivers of the patients tested positive for COVID-19 [15]. This was also the case for our patient when his mother tested positive twice before his COVID-19 second swab turned positive. Thus, the possibility of contracting COVID-19 from a caregiver remains a challenge, and further preventive measures are advised [15]. Another study was conducted by an Italian team, which reported 5 cases of cancer in their pediatric hemato-oncology department, all of whom showed a mild form of SARS-CoV-2 and with each being successfully cured: 2 of them in the hospital and 3 at home [16].

Here, we strengthen the hypothesis that hemato-oncology children with COVID-19 are not likely to develop a severe form of SARS-CoV-2. The explanation for the mild form of COVID-19 in child cancer patients could be due to the following: (1) the possibility of a weaker immune response, which limits the trigger of the inflammatory reaction that is required to cause the damage of the disease; (2) the fact that immunocompromised patients are often required to be socially isolated, limiting the chances of them contracting the disease; (3) in general, the role of innate immunity in children might be the reason for milder forms of the

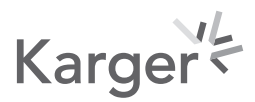


Case Reports in Oncology
Case Rep Oncol 2021;14:1031-1039

\begin{tabular}{l|l}
\hline DOI: $10.1159 / 000516442$ & @ 2021 The Author(s). Published by S. Karger AG, Basel \\
\hline
\end{tabular} www.karger.com/cro

Arafat et al.: COVID-19, Acute Lymphoblastic Leukemia, and Down Syndrome
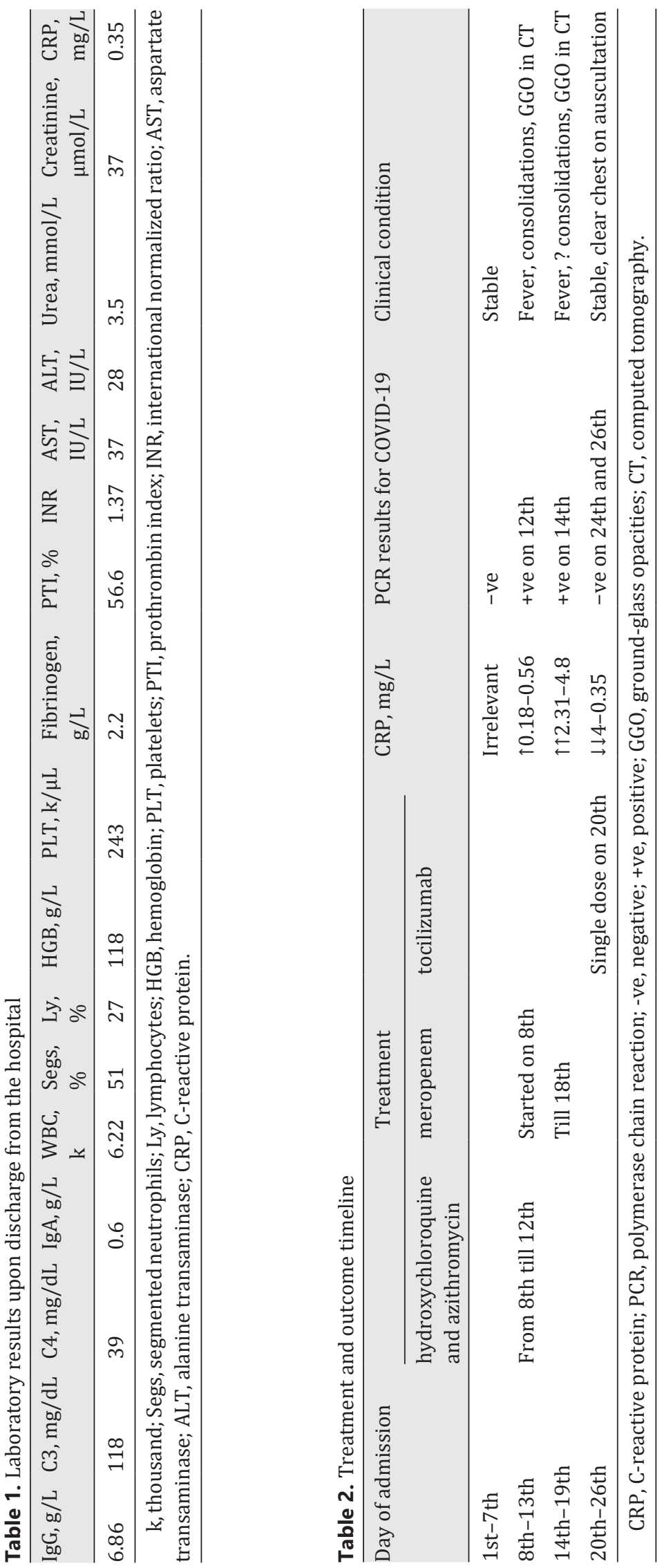

Karger' 
disease; (4) in children, compared to adults, the low binding ability and the expression levels of angiotensin-converting enzyme-2 (which are necessary for SARS-CoV-2 to bind and initiate its inflammation process) have most likely played a key role in the explanation of mild forms of the disease in children $[16,17]$. Nevertheless, the possibility of severe cases and even fatalities in children with underlying health conditions cannot be thoroughly ruled out, as we look at lessons we have learned from the previous Middle East respiratory syndrome epidemics [18].

Interestingly, the CT results were not truly representative of our patient's general condition, and his $\mathrm{SPO}_{2}$ saturation did not fall below 96\%, while the CT results showed multiple infiltrations, consolidations, and GGO on both lungs. Similar to other reports from Korea and China [19, 20], what was different from that reported was that CT findings that are specific to COVID-19 were limited to a single lung segment, unlike the presentation we had with our patient, which could be due to the underlying health conditions that were present in our case. We limited performing CT scans to 2 sets with consideration of the potential risks of radiation as was suggested by a recent study [21]. The severity of SARS-CoV-2 infection in DS children is unknown, with a few reports of a severe form of the disease in adult DS cases and the suggestion of paying close attention to the potential risk of developing cytokine storm in these patients [22, 23].

Reduction of chemotherapy in leukemia patients with DS due to the fear of treatmentrelated toxicities has been an area of debate, with some reports suggesting a reduction of the dose and others seeing no significant difference in outcome between those with dose reduction and the control group [24]. Careful consideration for the unique presentation of our case and the underlying health conditions led us to recommend a reduction of the dose of chemotherapy by one-third, in case of another relapse that required continuation of the chemotherapy, and with consideration for treatment delay of $>7$ days, as the incubation period of SARS-COV-2 is between 2 and 7 days [25]. This was recommended by a recent study from China [25].

Decisions to use antiviral therapy should be tailored to a case-by-case basis, with consideration for the clinical presentation, disease severity, and underlying health conditions. Another area of recent debate was the efficacy of hydroxychloroquine with or without a macrolide in treating COVID-19 patients. A recent study in adults (which is still being peer reviewed) showed that patients with COVID-19 who were treated with hydroxychloroquine had their time to clinical recovery significantly shortened and pneumonia improved compared to the control group [26]. A large recent study on adults from The Lancet examined the efficacy of hydroxychloroquine or chloroquine with or without a macrolide for treatment of COVID-19 on 14,888 patients compared to a control group of 81,144 patients, which found no benefit for either hydroxychloroquine or chloroquine alone or with a macrolide in treating COVID-19. Moreover, patients in the treatment group were associated with increased in-hospital deaths and ventricular arrhythmias. The study stirred up a lot of controversy and was recently retracted [27]. Reports of the efficacy of hydroxychloroquine with or without a macrolide in children are now lacking. Our patient who was initially treated with hydroxychloroquine and azithromycin did not show improvement, and the time to clinical recovery did not show any significant outcome, with his PCR being elevated and his CT findings worsening. It was not until tocilizumab was prescribed that dramatic improvement was noticed, and a successful recovery was achieved on the 4th day of prescription and confirmed on the 6th day of administration, with his second oropharyngeal swab testing negative for COVID-19 by PCR.

Promising results of the efficacy of the IL- 6 inhibitor tocilizumab in the treatment of COVID-19 have been reported. A recent study on adults showed that in severe COVID-19 cases, tocilizumab resulted in a quick decline in inflammatory markers and a reduction of the requirements for ventilation support [28]. An Italian study on adults with COVID-19 demonstrated positive results when tocilizumab was used in the early stages of the disease in terms

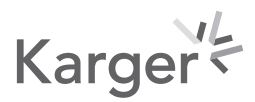


of better survival rates compared to the control group [28]. A study of 100 adults with severe COVID-19 revealed significantly positive results with overall clinical improvement and clearance of diffuse bilateral opacities on chest X-ray in $61 \%$ of the cases [29].

A prospective clinical trial conducted on pediatric B-cell ALL patients found that riskadapted administration of preemptive tocilizumab $(8-12 \mathrm{mg} / \mathrm{kg}$ ) once high, persistent fever developed had reduced the incidence of severe cytokine release syndrome without having an impact on the safety or antitumor efficacy of tisagenlecleucel that was given to those patients [30], which adds momentum to our suggestion of considering a single dose of tocilizumab (8 $\mathrm{mg} / \mathrm{kg}$ ) in severe cases of COVID-19, ALL, and DS to prevent the incidence of severe cytokine release syndrome.

Although there has been no dedicated study to investigate the efficacy of tocilizumab in treating pediatrics cases of COVID-19 and ALL, the promising results of these recent studies on adults and pediatric patients bring hope for patients with severe COVID-19, but the cost of the drug remains an obstacle to having it widely used, and more clinical trials are required to prove its clinical efficacy. Recent studies have suggested that pediatric cases with cancer and COVID-19 are not at any greater risk of developing severe forms of the disease than the general pediatric population [31], and thus further supportive therapy that would be tailored for pediatric oncology patients and COVID-19 is not really required.

\section{Conclusion}

ALL children with COVID-19 tend to have a good prognosis and a mild form of the disease, although children with underlying health conditions might be presented with severe forms of the disease. CT in children should be performed in suspected cases since many pediatric cases have severe abnormalities in their CT scans while their clinical conditions do not represent the underlying pathology of their chest, and bilateral ground-glass opacities are not unlikely to happen in children. We recommend the use of a single-dose tocilizumab in severe cases of COVID-19, ALL, and DS in children.

\section{Acknowledgment}

We are delighted to have the opportunity to thank all of our colleagues who made this work possible, and we would also like to thank our patient and his caregiver. In addition, we would like to give a special thanks to the Kazan State Medical University Board.

\section{Statement of Ethics}

Our work was conducted ethically in accordance with the World Medical Association Declaration of Helsinki. Written informed consent was collected from our patient and their caregiver (mother) for publication of this case report and any accompanying images. This case report was approved by Kazan Medical State University and the Republican Children's Clinical Hospital Medical Ethics Committee.

\section{Conflict of Interest Statement}

The authors have no conflicts of interest to declare.

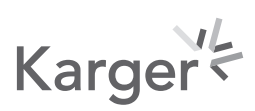




\section{Case Reports in Oncology}

Case Rep Oncol 2021;14:1031-1039

\begin{tabular}{l|c|c|}
\hline DOI: $10.1159 / 000516442$ & $\odot 2021$ The Author(s). Published by S. Karger AG, Basel
\end{tabular} www.karger.com/cro

\section{Funding Sources}

No funding was secured for this study.

\section{Author Contributions}

Dr. Arafat conceptualized and designed the study, coordinated data collection, drafted the initial manuscript, and critically reviewed the manuscript for important intellectual content. Prof. Sadykova conducted the clinical work, coordinated data collection, and reviewed and revised the manuscript. Drs. Ayrat Ziatdinov, Svetlana Senek, and Natalya Samoilova1Brown designed the data collection instruments, collected data, carried out the initial analyses, and reviewed and revised the manuscript. Dr. Tamara Makarova reviewed the manuscript for important intellectual content. All authors approved the final manuscript as submitted and agree to be accountable for all aspects of the work.

\section{References}

1 Wu Z, McGoogan JM. Characteristics of and important lessons from the Coronavirus Disease 2019 (COVID-19) outbreak in China: summary of a report of 72,314 cases from the chinese center for disease control and prevention. JAMA. 2020;323(13):1239-42. Published online ahead of print 2020 Feb 24.

2 CDC COVID-19 Response Team. Coronavirus disease 2019 in children: United States, February 12-April 2, 2020. MMWR Morb Mortal Wkly Rep. 2020;69(14):422-6. Published 2020 Apr 10.

3 Hunger SP, Lu X, Devidas M, Camitta BM, Gaynon PS, Winick NJ, et al. Improved survival for children and adolescents with acute lymphoblastic leukemia between 1990 and 2005: a report from the children's oncology group. J Clin Oncol. 2012;30:1663-9.

4 Hunger SP, Mullighan CG. Acute lymphoblastic leukemia in children. N Engl J Med. 2015;373(16):1541-52.

5 Smith M, Arthur D, Camitta B, Carroll AJ, Crist W, Gaynon P, et al. Uniform approach to risk classification and treatment assignment for children with acute lymphoblastic leukemia. J Clin Oncol. 1996;14:18-24.

6 Whitlock JA, Sather HN, Gaynon P, Robison LL, Wells RJ, Trigg M, et al. Clinical characteristics and outcome of children with down syndrome and acute lymphoblastic leukemia: a children's cancer group study. Blood. 2005;106:4043-9.

7 Zwaan CM, Kaspers GJ, Pieters R, Hählen K, Janka-Schaub GE, van Zantwijk CH, et al. Different drug sensitivity profiles of acute myeloid and lymphoblastic leukemia and normal peripheral blood mononuclear cells in children with and without down syndrome. Blood. 2002;99(1):245-51.

8 O’Brien MM, Taub JW, Chang MN, Massey GV, Stine KC, Raimondi SC, et al. Cardiomyopathy in children with down syndrome treated for acute myeloid leukemia: a report from the Children's Oncology Group Study POG 9421. J Clin Oncol. 2008;26(3):414-20.

9 Pérez-Padilla R, Fernández R, García-Sancho C, Franco-Marina F, Aburto O, López-Gatell H, et al. Pandemic (H1N1) 2009 virus and Down syndrome patients. Emerging Infect Dis. 2010;16(8):1312-4.

10 Löwensteyn YN, Phijfer EWEM, Simons JVL, Scheltema NM, Mazur NI, Nair H, et al. Respiratory syncytial virusrelated death in children with Down syndrome: the RSV GOLD study. Pediatr Infect Dis J. 2020;39(8):665-70.

11 Zhang C, Wu Z, Li JW, Zhao H, Wang GQ. The cytokine release syndrome (CRS) of severe COVID-19 and Interleukin-6 receptor (IL-6R) antagonist Tocilizumab may be the key to reduce the mortality. Int J Antimicrob Agents. 2020;29:105954.

12 Chen Z, Xiong H, Li JX, Li H, Tao F, Yang YT, et al. COVID-19 with post-chemotherapy agranulocytosis in childhood acute leukemia: a case report. Zhonghua Xue YeXue Za Zhi. 2020;41(4):341-3. Published online Mar 9 (in Chinese).

13 Ferrari A, Zecca M, Rizzari C, Porta F, Provenzi M, Marinoni M, et al. Children with cancer in the time of COVID19: an 8-week report from the six pediatric onco-hematology centers in Lombardia, Italy. Pediatr Blood Cancer. 2020;67(8):e28410.

14 Sahi PK, Chandra J. Pediatric hemato-oncology care amid the COVID-19 pandemic. Indian J Pediatr. 2021 Mar; 88(3):221-4. Epub 2021 Jan 9.

15 Boulad F, Kamboj M, Bouvier N, Mauguen A, Kung AL. COVID-19 in children with cancer in New York city. JAMA Oncol. 2020;6(9):1459-60. Published online May 13.

16 Balduzzi A, Brivio E, Rovelli A, Rizzari C, Gasperini S, Melzi ML, et al. Lessons after the early management of the COVID-19 outbreak in a paediatric transplant and haemato-oncology centre embedded within a COVID-19 dedicated hospital in Lombardia, Italy. Bone Marrow Transplant. 2020;55(10):1900-5. In press.

17 Dong Y, Mo X, Hu Y, Qi X, Jiang F, Jiang Z, et al . Epidemiological characteristics of 2,143 pediatric patients with 2019 coronavirus disease in China. Pediatrics. 2020.

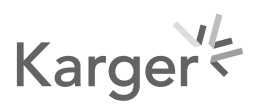


18 Thabet F, Chehab M, Bafaqih H, Al Mohaimeed S. Middle East respiratory syndrome coronavirus in children. Saudi Med J. 2015;36(4):484-6.

19 Feng K, Yun YX, Wang XF, Yang GD, Zheng YJ, Lin CM, et al. [Analysis of CT features of 15 children with 2019 novel coronavirus infection]. Zhonghua Er Ke Za Zhi. 2020;58:275-8. Chinese.

20 Park JY, Han MS, Park KU, Kim JY, Choi EH. First pediatric case of coronavirus disease 2019 in Korea. J Korean Med Sci. 2020 Mar;35(11):e124.

21 Espinosa JM. Down syndrome and COVID-19: A perfect storm? Cell Rep Med. 2020;1(2):100019.

22 De Cauwer H, Spaepen A. Are patients with Down syndrome vulnerable to life-threatening COVID-19? Acta Neurol Belg. 2020;1-3. Published online ahead of print 2020 May 22.

23 Hefti E, Blanco JG. Pharmacokinetics of chemotherapeutic drugs in pediatric patients with down syndrome and leukemia. J Pediatr Hematol Oncol. 2016;38(4):283-7.

24 He Y, Lin Z, Tang D, Yang Y, Wang T, Yang M. Strategic plan for management of COVID-19 in paediatric haematology and oncology departments. Lancet Haematol. 2020;7(5):e359-62.

25 Chen Z, Hu J, Zhang Z, Jiang S, Han S, Yan D, et al. Efficacy of hydroxychloroquine in patients with COVID-19: results of a randomized clinical trial. medRxiv. 2020.

26 Mehra MR, Desai SS, Ruschitzka F, Patel AN. Retracted: hydroxychloroquine or chloroquine with or without a macrolide for treatment of COVID-19: a multinational registry analysis. Lancet. 2020;S0140-6736(20): 31180-6. Published online ahead of print 2020 May 22.

27 Alattar R, Ibrahim TBH, Shaar SH, Abdalla S, Shukri K, Daghfal JN, et al. Tocilizumab for the treatment of severe coronavirus disease 2019. J Med Virol. 2020. Published online ahead of print 2020 May 5.

28 Capra R, De Rossi N, Mattioli F, Romanelli G, Scarpazza C, Sormani MP, et al. Impact of low dose tocilizumab on mortality rate in patients with COVID-19 related pneumonia. Eur J Intern Med. 2020;76:31-5.

29 Toniati P, Piva S, Cattalini M, Garrafa E, Regola F, Castelli F, et al . Tocilizumab for the treatment of severe COVID-19 pneumonia with hyperinflammatory syndrome and acute respiratory failure: a single center study of 100 patients in Brescia, Italy. Autoimmun Rev. 2020;19(7):102568.

30 Kadauke S, Myers RM, Li Y, Aplenc R, Baniewicz D, Barrett DM, et al . Risk-adapted preemptive tocilizumab to prevent severe cytokine release syndrome after CTL019 for pediatric B-cell acute lymphoblastic leukemia: a prospective clinical trial. J Clin Oncol. 2021 Mar 10;39(8):920-30. Epub 2021 Jan 8.

31 Millen GC, Arnold R, Cazier JB, Curley H, Feltbower RG, Gamble A, et al. Severity of COVID-19 in children with cancer: report from the United Kingdom paediatric coronavirus cancer monitoring project. Br J Cancer. 2021 Feb;124(4):754-9. Epub 2020 Dec 10. 